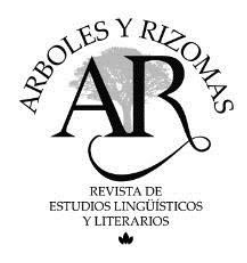

Árboles y Rizomas Vol. I, No 1 (enero-junio, 2019): 24-34

Universidad de Santiago de Chile, ISSN 0719-9805

https://doi.org/10.35588/ayr.v1i1. 3675

\title{
La España de Fernando Iwasaki, setenta años después de la España de César Vallejo ${ }^{1 *}$
}

\author{
Fernando Iwasaki’s Spain, Seventy Years after César Vallejo's Spain \\ Carmen Tisnado ${ }^{2 *}$
}

\begin{abstract}
Resumen
España, aparta de mí estos premios (2009) de Fernando Iwasaki, sin duda, establece una conexión con la muy conocida obra del poeta peruano César Vallejo, España, aparta de mí este cáliz. En este artículo se establece una comparación entre la voz lírica del poemario de Vallejo y la voz narrativa de la colección de Iwasaki. En el estudio de esta comparación se explora la perspectiva que ofrece España en dos tiempos diferentes. En otras palabras, ¿qué relación trasatlántica propone Iwasaki? ¿Cómo se puede comparar esta relación con la posible relación que propone Vallejo? ¿Qué miradas (perspectivas) de España se representan en los relatos de Iwasaki?
\end{abstract}

Palabras clave: España, Sudamérica, globalización, inmigrante, escritura

\begin{abstract}
España, aparta de mí estos premios [Spain, Take These Awards from Me] (2009) by Fernando Iwasaki establishes, no doubt, a connection to the well-known text by Peruvian poet César Vallejo, España, aparta de mí este cáliz[Spain, Take This Cup from Me]. This paper compares the lyric voice in Vallejo's poem and the narrative voice in Iwasaki's text. This comparison leads to an exploration of the way in which Spain is represented in two different historical times. In other words, what is the Transatlantic relation posed by Iwasaki? How can we compare this relation to the possible relation suggested by Vallejo? What views of Spain does Iwasaki represent in the narratives?
\end{abstract}

Keywords: Spain, South America, globalization, immigrant, writing

En el discurso de apertura de un coloquio literario realizado en la Casa de la Literatura Peruana, el profesor Elton Honores, al referirse a Fernando Iwasaki, señaló que en Perú se piensa en él como en un autor peruano que vive en España, y en España lo consideran un escritor

\footnotetext{
1* Una versión de este trabajo fue presentada en el VII Congreso de la Asociación Internacional de Peruanistas: "Perú al pie del orbe. Literaturas, mitos e historias." 7-9 de octubre, 2015. Universidad de Poitiers, Francia.

${ }^{2 *}$ Franklin \& Marshall College, Pensilvania, Estados Unidos. E-mail: carmen.tisnado@fandm.edu
} 
Carmen Tisnado

español que nació en el Perú. En efecto, Iwasaki (1961), autor de dos novelas y ocho colecciones de relatos, además de ensayos históricos, literarios, y artículos periodísticos, nació en Lima y reside en Sevilla desde 1989. Debido a su ascendencia japonesa, es muy posible que en ambos países lo perciban también como japonés. En otras palabras, Iwasaki simboliza lo que es el "mundo globalizado." Esta personificación del mundo globalizado está representada en su colección de relatos, España, aparta de mí estos premios (2009).

No creo que sea posible empezar la lectura del libro de Iwasaki sin que se nos venga en mente el poemario de César Vallejo, España, aparta de mí este cáliz (1937). El título del texto de Iwasaki no es gratuito y esta obra, de hecho, entabla "conversación" con el poemario de Vallejo. Los títulos de ambas obras apelan a España, pero existe un espacio temporal de setenta y dos años entre la España de Vallejo y la de Iwasaki. Aunque el territorio sea el mismo, las Españas de ambos autores son sustancialmente diferentes, tal como es la relación que cada texto entabla con España. Es necesario considerar la España de Vallejo para comprender mejor la de Iwasaki.

Al leer "Himno a los voluntarios de la república," el primer poema de España, aparta de mí este cáliz, es evidente que la voz poética trata por igual a los voluntarios españoles como a los extranjeros, aquellos brigadistas internacionales que luchaban por la misma utopía. Al inicio del poema, sin embargo, la voz se dirige exclusivamente al español:

Voluntario de España, miliciano

de huesos fidedignos, ...

En las siguientes estrofas, la voz poética define al "voluntario de España." Así, tenemos que en diferentes versos, apela a distintos grupos de personas, españoles quizá, usando por lo general la forma singular en tanto que todos forman un ente común:

- Proletario que mueres de universo

- Liberador ceñido de grilletes

- Campesino caído con tu verde follaje por el hombre

- Constructores, agrícolas, civiles y guerreros

- Obrero, salvador, redentor nuestro

Vallejo define a los defensores de la Segunda República como a aquellos pertenecientes a o que se solidarizan con el grupo social explotado, muchas veces derrotado, pero que al mismo tiempo, será el agente de su propia redención social. En versos posteriores vemos que el apelativo es diferente. Por ejemplo, en la siguiente estrofa, la voz poética no le habla exclusivamente al "voluntario de España" sino que extiende su llamado a voluntarios de otras nacionalidades específicas y luego lo hace mucho más general, más bien refiriéndose a la función que desempeñan todos los combatientes, sin que importe su nacionalidad. Su uso del singular es especialmente efectivo en este sentido:

¡Voluntario italiano, entre cuyos animales de batalla un león abisinio va cojeando!

\footnotetext{
${ }^{3}$ Los versos del poemario de Vallejo no tienen paginación en este trabajo debido a su publicación en línea. Ver datos bibliográficos en la sección "Obras Consultadas."
} 
Carmen Tisnado

¡Voluntario soviético, marchando a la cabeza de tu pecho universal!

Voluntarios del Sur, del Norte, del Oriente

y tú, el occidental, cerrando el canto fúnebre del alba!

¡Soldado conocido, cuyo nombre

Desfila en el sonido de un abrazo!

¡Combatiente que la tierra criara ...

Esta estrofa, al condenar implícitamente la invasión de Italia a Etiopía (1935-36) en sus dos primeros versos, alude precisamente al poder internacional de los que luchan por el interés común de las clases trabajadoras. Los signos de exclamación sirven como el retoque de los tambores que acompaña la marcha de los brigadistas internacionales, en unión con los voluntarios españoles, como "un solo combatiente que la tierra criara."

A pesar de la fuerza que la voz poética le otorga a los soldados en "Himno a los voluntarios de la república," a lo largo del poemario se expresa el fracaso del proyecto común. Así, en el último de los poemas, "España, aparta de mí este cáliz," que le da título al poemario, la voz poética ya no se dirige a los voluntarios republicanos sino a los "niños del mundo:"

¡Niños del mundo, está

la madre España con su vientre a cuestas;

$[\ldots]$

Si cae — digo, es un decir- si cae

España, de la tierra para abajo,

niños ¡cómo vais a cesar de crecer!

¡cómo va a castigar el año al mes!

¡cómo van a quedarse en diez los dientes,

en palote el diptongo, la medalla en llanto!

¡Cómo va el corderillo a continuar

atado por la pata al gran tintero!

¡Cómo vais a bajar las gradas del alfabeto

hasta la letra en que nació la pena!

Al igual que cuando la voz se dirige a los brigadistas, el mensaje no se restringe a los niños españoles sino que se abre a los niños del mundo y, por tanto, el poemario continúa de algún modo el llamado al proyecto internacional en que consistió la Segunda República. Este último poema examina el futuro incierto que le espera a la juventud después del fracaso de la lucha por la utopía republicana. La incertidumbre radica, entre otras cosas, en el desconocimiento que existe en el ahora del poema en cuanto a la responsabilidad que los niños asumirán frente a España cuando lleguen a una edad apropiada para luchar por ella. Ahora, dice la voz poética, la situación de España, con el paso del tiempo, puede devenir en un obstáculo para el desarrollo tanto a nivel físico/biológico, como, peor aún, a nivel social y humano, pues se vislumbra la ignorancia que viene con la censura.

Es en los dos últimos versos del poema, y por tanto del poemario, donde el pesimismo que ha definido casi todo el poema se transforma en un optimismo incipiente: "España cae digo, es un decir - / salid, niños del mundo; id a buscarla!" Se ve aquí que el proyecto de la 
Carmen Tisnado

Segunda República ha fracasado, pero existe cierta esperanza en el futuro, representado por los niños, a un nivel global, internacional. Ahora depende de ellos, pero la utopía aún puede suceder.

En el penúltimo de los poemas, desde su título - "Cuídate, España" - vemos que la voz apela a España en forma directa y hace una suerte de advertencia de que no se puede percibir el mundo a través de oposiciones en las que lo bueno reside en un extremo y lo malo en el extremo opuesto. En un país destruido por una lucha interna todos terminan siendo víctimas y victimarios:

¡Cuídate España, de tu propia España!

$[\ldots]$

¡Cuídate de la víctima a pesar suyo,

del verdugo a pesar suyo

y del indiferente a pesar suyo!

$[\ldots]$

¡Cuídate del futuro!

España, de modo figurado, asume el papel de víctima y a la vez de victimario. Por lo mismo, se hace difícil confiar plenamente en ella o en quien diga representarla. La voz poética exhorta a quien la escuche a que use su criterio propio, a que evalúe con claridad las situaciones, y a que no confíe ciegamente en nadie.

Dentro de este contexto podemos comprender mejor el sentido de Vallejo al haber adoptado la frase atribuida a Jesucristo en varios de los Evangelios para titular el último de los poemas y a la vez su poemario total. En el contexto de la frase bíblica, es especial en el Evangelio según san Lucas (22,39-46), Jesucristo, en su última oración en el Huerto de los Olivos, exclama: "Padre, si quieres, aparta de mí este cáliz; pero que no se haga mi voluntad, sino la tuya." Esta súplica acentúa la resignación de Cristo. El "cáliz," entre otras cosas, representa su sufrimiento ante la absoluta soledad frente al aparente abandono de todos los que dicen profesarle amor. En la obra de Vallejo, España, al igual que el padre en la oración del Huerto de los Olivos, asume papel de agente y su acción genera sufrimiento tanto para los españoles como para los brigadistas y simpatizantes internacionales. Vallejo implica que sólo será la propia España, ubicada en un contexto internacional y reinventada a través de la futura acción de sus niños y de niños de otros países, la que podrá liberar de sus sufrimientos a la España vigente. Como señala Julio Ortega (1982, p.269), "con los materiales de la tragedia Vallejo escribe un texto del fin de los tiempos que se responde a sí mismo transformándose en una alternativa utópica". Es pues evidente que la España a la que se dirige el poemario de Vallejo es la España distópica, la España del sufrimiento - una España agonizante cuya esperanza de utopía sólo podrá anticiparse para un futuro. Aunque le adjudica cierta responsabilidad por el sufrimiento de su tiempo presente, la voz también le suplica generosidad y compasión.

De manera radicalmente diferente, la voz narrativa de España, aparta de mí estos premios, de Fernando Iwasaki (2009, todas las citas refieren a esta edición) no suplica nada. Más bien, se presenta con autoridad suficiente para dar sugerencias o mandatos. Además, la España a la que alude el texto evoca una igualdad horizontal entre hispanoamericanos y españoles, quienes ocupan un mismo lugar en el que comparten necesidades similares: "Gracias al tumulto de premios desperdigados por toda la geografía española, cientos de escritores latinoamericanos y no pocos aborígenes (en este caso, españoles), pueden comer caliente, llegar a fin de mes e incluso 


\section{Carmen Tisnado}

comprarse un ordenador nuevo" (Iwasaki, 2009, p.13). Por un lado, la voz Iwasaki reconoce la generosidad de España, que organiza sus múltiples premios literarios. Por otro lado, el uso que hace de la palabra "aborigen" para referirse a los españoles es hasta cierto punto provocativo. El primer significado que da a la palabra la Real Academia Española es bastante directo: "originario del suelo en que vive" (p. 7). Es la segunda acepción la que alude a las atribuciones negativas que se le dan al vocablo con respecto a los aborígenes de América: incivilizados, primitivos, ignorantes, estúpidos: "Dícese del primitivo morador de un país, por contraposición a los establecidos posteriormente en él” (p. 7). La definición es descriptiva y no tiene connotaciones específicas, pero bastaría leer el Diario de Colón para apreciar la manera en que el español cosifica al aborigen y lo trata como un posible servidor del europeo desde un inicio. ${ }^{4}$ Iwasaki revierte este modelo. "En este caso," ahora, son los españoles los que son primitivos, tanto por establecer tantos premios literarios que carecen de sentido como por estar en la misma condición de necesidad que el hispanoamericano al que antes denominaban peyorativamente sudaca y, más aún, por ser quienes reciben sugerencias de un extranjero.

España, aparta de mí estos premios, se inicia y acaba con sugerencias. El texto termina con sugerencias para los escritores, presentadas usando el modo imperativo en el "Decálogo del concursante consuetudinario (y probablemente ultramarino)" (Iwakasi, 2009, pp. 155-6). Aquí, al igual que los voluntarios de las brigadas internacionales, los escritores que presentan sus obras a concursos literarios en España provienen de una variedad de países. Estamos, pues, frente a dos grupos integrados por personas de orígenes diversos. En ambos casos, estas personas luchan por algo. El grupo de Vallejo empuña las armas formando un conjunto que, a pesar de su heterogeneidad, imagina un fin común - la utopía que los trasciende. El grupo de Iwasaki se distingue por el individualismo ya que se trata de personas en competencia entre sí, dispuestas a recurrir a trucos o engaños para ganar el premio que los beneficie de manera individual.

España, aparta de mí estos premios es una colección de siete cuentos con una organización idéntica: cada uno empieza con la convocatoria a un concurso literario hecha por una institución regional de España. Las bases para la presentación de cuentos están claramente indicadas, así como el monto específico del premio. A continuación se presenta el cuento ganador, seguido por las Actas del Jurado en las que siempre se expone la disconformidad de un miembro con respecto a la decisión final. Al terminar de leer los siete relatos podemos apreciar

\footnotetext{
${ }^{4}$ Ellos andan todos desnudos como su madre los parió, y también las mugeres, aunque no vide más de una farto moça, y todos los que yo vi eran todos mançebos, que ninguno vide de edad de más de XXX años, muy bien hechos, de muy fermosos cuerpos y muy buenas caras, los cabellos gruessos cuasi como sedas de cola de cavallo e cortos. Los cabellos traen por ençima de las cejas, salvo unos pocos detrás que traen largos, que jamás cortan. d'ellos se pintan de prieto, y [d']ellos son de la color de los canarios, ni negros ni blancos, y d'ellos se pintan de blanco y d'ellos de colorado y d'ellos de lo que fallan; y d'ellos se pintan las caras, y d'ellos todo el cuerpo, y d'ellos solos los ojos, y d'ellos solo el nariz. Ellos no traen armas ni las cognosçen, porque les amostré espadas y las tomavan por el filo y se cortavan con ignorançia. No tienen algún fierro; sus azagayas son unas varas sin fierro y algunas d'ellas tienen al cabo un diente de peçe, y otras de otras cosas. Ellos todos a una mano son de buena estatura de grandeza y buenos gestos, bien hechos. Yo vide algunos que tenían señales de feridas en sus cuerpos, y les hize señas qué era aquello, y ellos me amostraron cómo allí venían gente de otras islas que estavan açerca y les querían tomar y se defendían. Y yo creí e creo que aquí vienen de tierra firme a tomados por captivos. Ellos deven ser buenos servidores y de buen ingenio, que veo que muy presto dizen todo lo que les dezía. Y creo que ligeramente se harían cristianos, que me pareçió que ninguna secta tenían.
} 
que éstos constituyen variaciones de un solo argumento - es "el mismo texto refrito varias bases según las veces y viceversa," (p. 13) según palabras del mismo Iwasaki. Se puede apreciar el humor con que el autor se refiere al reciclaje de los cuentos, en los que el orden y la estructura no importan con tal que cumplan algunos de los requisitos del certamen, por muy irrisorios que sean.

Tanto la convocatoria como las actas del jurado de cada cuento tienen un estilo florido. En cada caso, la idea es realzar un lugar, un episodio histórico, o el toque gastronómico de algún municipio de España. El humor de la colección no sólo está presente en las historias de cada uno de los siete relatos sino que además se desprende de las convocatorias de cada certamen, con sus exigencias ridículas y de las actas del jurado, donde, como indiqué, siempre se encuentra el desacuerdo de uno de los miembros. Las bases de cada concurso son muy similares. Cabe resaltar la ironía implícita en la convocatoria número 2, que exige la originalidad y condición inédita del texto pero que, sin embargo, es la misma convocatoria que se presenta en los siete concursos referidos en cada uno de los relatos.

Los siete relatos se sitúan entre un prólogo y un epílogo, aunque ambos pertenezcan a categorías diferentes. El prólogo es una introducción que el mismo autor hace a su obra, y en él Fernando Iwasaki hace referencia directa a los "premios desperdigados por toda la geografía española" y a la manera en que los cuentos premiados son, en muchos casos, "homotextuales" (p. 13). El epílogo proviene de la voz del autor implícito que crea Iwasaki. De hecho, si los relatos son el mismo, el autor es uno, y es él quien tiene la autoridad para indicar cuáles son las leyes del éxito de los concursos literarios, y las ofrece en su "Decálogo del Concursante Consuetudinario (y probablemente ultramarino" (p.155).

Al hacer una lectura regresiva, son evidentes las manifestaciones explícitas de estas diez normas en los siete relatos de la colección. Por ejemplo, la segunda ley del "Decálogo" es: "Firma siempre con seudónimos femeninos, pero que sean sugerentes. Jamás explícitos. El recato atrae más" (p. 155). Así, los seudónimos para cada uno de los siete relatos son, en orden de presentación: Manolita Chen, Rosa de Luxemburgo, Kiki de Montparnasse, Madame Butterfly, Biri-Diana, La Chef Guevara, y La Lola que se fue de los puertos.

Es de importancia subrayar la tercera ley del "Decálogo," que dice: "Escribe un cuento que sea como una 'célula madre' literaria que puedes clonar para cada concurso. No te preocupes. Los clones siempre salen mejores que el original" (p. 155). Se puede acordar que "El haiku del brigadista" -el primer cuento que aparece en la colección- es la "célula madre literaria" que luego va a reescribirse para los otros seis certámenes. "El haiku" cuenta la historia de Makino Yoneyama, japonés que ha permanecido escondido en la Cueva de la Pileta durante casi setenta años. Cuando lo encuentran, lo arrestan bajo sospechas de terrorista, pero luego averiguan que es más bien "un heroico miembro de las Brigadas Internacionales, acaso el último soldado caído en defensa de la Segunda República" (p. 22). Ante tal descubrimiento, las autoridades del Ayuntamiento de Benaoján, institución que convoca y patrocina el IV Certamen de Cuentos Espeleológicos "Cueva de la Pileta," le brindan los honores que piensan que se merece. Muy poco tiempo después, Yoneyama entra en estado de coma, y un grupo de multimedia adquiere derechos para transmitir "minuto a minuto, las incidencias del coma profundo" (p. 25). El programa "El Durmiente Solidario" alcanza lo más alto del rating y surge una obsesión nacional por seguirlo. Poco tiempo después de despertar, Yoneyama, agobiado y desilusionado por la realidad que observa, se suicida.

El resto de cuentos son, en efecto, variaciones del mismo tema. Todos los protagonistas son japoneses recién descubiertos que han permanecido ocultos en un sitio famoso e importante 
de España. Por ejemplo, en "El kimono azul," Makoto Komatsubara está escondido en el Alcázar hace casi setenta años. En todos los cuentos tanto las autoridades como la población del lugar donde se realiza la acción tienen sospechas iniciales de los protagonistas. Así, en "La geisha cubista," se sospecha que Michiko Arakaki, japonesa escondida casi setenta años en el Ayuntamiento de Barcelona, es un fantasma. De igual manera, en todos los cuentos la multimedia crea programas especiales que elevan los ratings de los canales de televisión. De este modo, en "El sake del pelotari," el rating del programa "Vascos sin fronteras" "comenzó a dispararse en forma diabólica" (p. 81) cuando en la presentación del Padre Joaquín Murrieta personaje secundario de los siete relatos- aparece su asistente Ahitori Tsurunaga. En todos los casos, los protagonistas mueren o desaparecen. En "La katana verdiblanca," por ejemplo, Makoto Komatsubara es uno de los protagonistas, muerto desde inicios de la historia, cuyas cenizas son transportadas por Makino Yoneyama (protagonista de "El haiku del brigadista").

Las semejanzas no sólo se dan en las historias sino también en los detalles estilísticos con que se las presentan. Por ejemplo, en el cuento "célula madre" ("El haiku del brigadista"), cuando televisan al protagonista en estado de coma, minuto a minuto, en el país entero, y sobre todo en la región donde se desenvuelven las acciones, las personas se obsesionan con él, y "como era de esperar, los libros sobre las vivencias y fatigas de Makino Yoneyama no tardaron en aparecer y en menos de un mes habían copado la lista de los diez libros más vendidos" (p. 26). La continuación es un verdadero despliegue de humor e ironía: "Por otro lado, la 'Yoneyamanía' provocó un efecto dominó que precipitó a la sociedad española sobre cualquier cosa que pareciera japonesa, como el manga, el ikebana, el sudoku y el flamenco. Nunca se leyó más a Kawabata, Mishima y Tanizaki. Nunca se comió más sushi en Alorcón de la Frontera" (p. 26). Los otros seis cuentos contienen exactamente el mismo patrón, y en algunas frases, aún sin saber la estrategia de la colección, se puede afirmar que se trata de plagio o de clonaje de cuentos aunque los detalles específicos varían. Así, en el cuento "El sushi melancólico," con respecto a la protagonista, el texto señala lo siguiente: "Como era de esperar, los libros sobre las vivencias y fatigas de Michiko Arakaki no tardaron en aparecer y en menos de un mes habían copado la lista de los diez libros más vendidos" (p. 130). Con una exactitud precisa, el texto continúa: "Por otro lado, la 'Arakakimanía' provocó un efecto dominó que precipitó a la sociedad vasca sobre cualquier cosa que pareciera japonesa, como el manga, el shodo, el kempo, y el flamenco. Nunca se leyó más a Tokutomi, Matsubara y Takeyama. Nunca se comió más sushi en Amorebieta" (p. 130). El "texto refrito" es evidente. Que este "texto refrito" gane siete certámenes literarios de diferentes regiones de España es una burla de la seriedad con que se convocan estos concursos y al mismo tiempo, paradójicamente, un elogio del ingenio y talento de aquel escritor que pueda adaptar su texto con tanta facilidad y que convenza a la mayoría de miembros de los respectivos jurados que su texto es digno de un premio.

Iwasaki elige como miembros del jurado de cada certamen a escritores reales, pero hay uno que aparece en todos - el escritor Hipólito Navarro. En muchas entrevistas le preguntan a Iwasaki por este miembro del jurado. En una que publica el Diario de Cádiz el autor responde lo siguiente: "Poli es puro jamón de pata negra y uno de mis mejores amigos. A Poli fue al único escritor que le anuncié que estaría en todos los jurados, precisamente porque somos amigos y tiene un gran sentido del humor" (sin paginación). El sentido de humor en este caso específico tiene un significado muy especial, pues la presencia de Navarro en todos los jurados debería servir de descalificación para todos los textos premiados, pues Navarro se tendría que dar cuenta de que los cuentos son todos el mismo con detalles cambiados para que coincidan con las bases 


\section{Carmen Tisnado}

de las convocatorias de cada concurso. De hecho, la burla no es de la persona del escritor Hipólito Navarro, sino de lo que significa el personaje del mismo nombre que crea Iwasaki. Este personaje ofrece una tomadura de pelo con respecto a la manera en que los jurados leen los cuentos, con una visión de túnel cuya única salida conduce al cumplimiento estricto de las bases del certamen.

El "flamenco" aparece como el único elemento supuestamente japonés que se repite en todos los cuentos. Sin embargo, gráficamente se hace explícito que "flamenco" no es una palabra japonesa, pues no se presenta en cursiva. Estamos aquí frente a otra tomadura de pelo que podría tener más de una interpretación. De todos modos, es una burla de la ignorancia o de la pasividad de la gente que acepta sin protestar que algo considerado representativo de la cultura española que es, en la mayoría de casos, su propia cultura- sea calificado de japonés.

En España, aparta de mí estos premios, se ve directamente la burla de toda sociedad que sucumbe a los caprichos de la maquinaria de los medios de comunicación masiva que ofrece múltiples alternativas de obsesión e idolatría -elementos cuyos efectos directos son la deshumanización de la población, que ya no puede pensar por sí misma y por lo tanto le es imposible distinguir lo evidente de lo que carece de fundamento. En palabras del mismo Iwasaki, publicadas en una entrevista en El país, "no es un libro que se burle de los premios, de España, o de los japoneses. No. La caricatura que resulta de la lectura del libro es la de la 'sociedad del espectáculo,' que es un fenómeno más bien mundial y que consiste en una banalización que lo invade todo, convirtiendo la realidad en 'reality show' y suplantando a la sociedad civil por la audiencia" (sin paginación). La colección de relatos sugiere dos tipos de audiencia. Por un lado, dentro del universo creado en los cuentos, están los espectadores de los siete programas de televisión cuyos protagonistas japoneses llegan a ser celebridades. Por otro, tenemos a los miembros de los jurados de los siete certámenes literarios, audiencia a la que se dirige cada uno de los textos. Se puede afirmar que en ningún caso la audiencia está bien informada o puede desenvolverse sobre la base de una reflexión madura.

No es mi intención analizar cada cuento de la colección ya que lo resaltante es que es "el mismo texto refrito siete veces." Más bien, me interesa explorar la manera en que el texto en su totalidad le habla a España, o se refiere a España, tanto a través de sus voces narrativas como a través de la voz del mismo Iwasaki, quien empieza su prólogo con una referencia directa al gran número de concursos literarios convocados en España y a los escritores españoles e hispanoamericanos que, gracias a estos concursos, pueden sobrevivir. Iwasaki confronta a quienes cuestionan si acaso los hispanoamericanos son capaces de escribir sobre aspectos de las diversas culturas de España, mencionando, no sin ironía, a "muchos cronistas de los siglos XV y XVI [que] perpetraron rocambolescas historias acerca del Nuevo Mundo sin salir de España" (p. 13). El uso forzado del verbo "perpetrar' adquiere un significado especial en la frase de Iwasaki. A nivel de connotación, el verbo alude a la apropiación del territorio, objetos, y hasta personas en que consistió la Conquista y que se derivó hasta la época de la Colonia. El uso del verbo "perpetrar," pues, consiste en una acusación al pasado trasatlántico. Sin embargo, el reclamo continúa, pues la frase sigue así: "ahora nos toca a nosotros, pero con menos margen de error, ya que contamos con Google, YouTube, televisión por cable y más de un millón de portales...” (pp. 13-14). ¿Quién es este "nosotros" hispanoamericano? ¿Se lo puede definir acaso como un ente grupal homogéneo? Aunque sea imposible calificarlo de una sola manera, el texto propone que se invierten los papeles, y ahora los hispanoamericanos se apropian de los premios que ofrece España. Además, la condición de desarraigo e insuficiencia no es exclusiva del inmigrante de 
Carmen Tisnado

Hispanoamérica, pues hay españoles que, a pesar de su origen, viven con las mismas carencias y necesidades.

Tanto en las afirmaciones que escribe en el Prólogo, como en las frases que crea en su ficción narrativa, Iwasaki nos dirige hacia la constante desintegración de la oposición español/hispanoamericano que, de hecho, en la actualidad no existe tal como se la entendía hace un tiempo no del todo lejano. La persona del autor mismo constituye un ejemplo de la anulación de esta oposición: es peruano y es considerado español al mismo tiempo y, más aún, tiene ascendencia japonesa.

España, aparta de mí estos premios nos invita a pensar en mucho más, sin embargo. Tanto Iwasaki como los cuentos que crea en su colección constituyen ejemplos palpables de la heterogeneidad vigente tanto en España como en Hispanoamérica. En efecto, en todos los cuentos la mayoría de personajes tienen al español como lengua materna, pero los papeles protagónicos los tienen personajes japoneses, que inicialmente los asumen como españoles. La colección entera pareciera alertar a sus lectores implícitos a que no presupongan nada, Por lo mismo, tampoco se puede asumir que todos los hispanohablantes de los siete cuentos son españoles. Algunos podrían ser hispanoamericanos. Es particularmente significativa la falta de mención explícita de hispanoamericanos, pero esto no revela una ausencia implícita. En parte, subrayar su presencia significaría acentuar su otredad, lo cual contribuiría a la perpetuación de la dicotomía español/hispanoamericano.

La colección de relatos de Iwasaki, pues, representa una integración tal que los personajes hispanoamericanos que pueda haber pasan desapercibidos. En plano diferente, el autor ejemplifica esta integración con su uso de la lengua. En el Prólogo explica que con los premios literarios algunos escritores podrían "comprarse un ordenador nuevo" (p. 13). Asimismo, al referirse a los cuentos, señala: "a nadie le gusta que salgan del armario esos cuentos premiados, precisamente porque son homotextuales" (p. 13). Es evidente la apropiación de terminología del discurso gay. Es quizá menos evidente la apropiación del léxico de España. Un peruano que habla en el Perú se compraría una "computadora" y sus cuentos, de hecho, saldrían del "closet."

El texto de Iwasaki representa la experiencia internacional en tres niveles. Primero, tenemos a un autor hispanoamericano de origen japonés. En un segundo nivel, se cree que este autor hispanoamericano-japonés es también considerado español. Por último tenemos, ya dentro del universo fícticio de los relatos, a personajes japoneses inmersos en ambientes totalmente españoles. Los protagonistas de cada relato comparten algunas características. Son japoneses que tienen cierta afiliación o inversión emocional con organizaciones o personas de España. Están literalmente escondidos durante mucho tiempo y por lo tanto ignoran muchos acontecimientos históricos - por ejemplo, el protagonista de "El haiku del brigadista" no se ha enterado del fin de la Guerra Civil. O son japoneses que han compartido tantos aspectos de su vida con otros españoles que no los perciben como extranjeros - por ejemplo, en "La katana verdiblanca," Makino y Makoto son floristas famosos en Sevilla a quienes todos conocen como el Quino y el Coto y nadie los piensa extranjeros.

En general, ya sea literal o figuradamente los protagonistas salen de su escondite y es tan grande la atención que se les da que adquieren el papel de celebridades. Es cuando son célebres que se acentúa su "otredad" y es precisamente aquí cuando los cuentos se tornan irreverentes y burlones. A pesar de la irreverencia y la burla, la colección de Iwasaki sugiere asuntos bastante serios. El texto presenta a una sociedad española que, debido al constante contacto con otras culturas, asume una posición que no tiene espacio para el purismo que antes la caracterizaba. Un 


\section{Carmen Tisnado}

texto que sugiere, aunque sea en chiste, que el flamenco es japonés y que los televidentes españoles se obsesionan con celebridades japonesas propone, sin duda, una visión globalizada. Lo europeo, lo hispanoamericano y lo asiático convergen en una colección de relatos que son aparentemente diferentes y aparentemente el mismo.

Volviendo al texto de Vallejo, podríamos decir que España, aparta de mí este cáliz trata al país, España, de un modo muy diferente del que la trata España, aparta de mí estos premios. El texto de Iwasaki no le suplica nada a España, como lo hace el de Vallejo. Quien habla en España, aparta de mí estos premios no es una voz adolorida que sufre por lo que atestigua. Es una voz que se ríe. Fernando Iwasaki declara lo siguiente: "hay dos Españas y sólo es posible escribir para una de las dos. Mi elección es clara y rotunda: siempre escribo para la España que sabe reírse de sí misma" (p.14). En una entrevista publicada en la revista Ojo seco, el autor declara su perspectiva sobre el humor:

El humor es un cristal, una manera de mirar y hay momentos en los que el humor debe convivir con otras maneras de mirar y con otros cristales para producir otros efectos. [...] El tipo de humor que a mí me interesa [es] un humor más de reflexión, que haga pensar y que aunque el lector pueda sentir una tentación de reírse, de pronto se dé cuenta que se está riendo de algo que es patético y terrible. Es la finalidad más alta del humor: hacer pensar. El humor debe servir como crítica, con un propósito. (pp. 4-5)

España, aparta de mí estos premios, de hecho, es un texto cuyo humor hace reír mucho, pero a la vez invita a pensar.

Tanto las palabras de Iwasaki como el texto que crea aluden a una sociedad distópica en la que impera la burla, la superficialidad, la ignorancia. La diferencia con la sociedad posible que alude Vallejo es palpable. En palabras de Julio Ortega con respecto al poemario de Vallejo, "la conciencia que asume la historia desde la poesía, se configura en la transformación de ambas: ambas -historia y poesía - se rehacen construyendo un texto extremo, un acto de fe donde la utopía social es también el retorno del lenguaje a su poder original de nombrar" (p. 270). El texto de Iwasaki, al contrario, representa el grado de manipulación que se puede hacer con un lenguaje que no necesariamente nombra, porque las palabras han perdido sus referentes. Las Españas de las dos Españas se presentan de una manera globalizada. La España de Vallejo se hermana con países de fuera. La de Iwasaki se plantea como un país en el que convergen personas diversas, pero no de una manera conjunta. Es más bien un país en el que sobrevive mejor el individuo ingenioso sin que le importe el bien común. Al final, los niños a los que les habla la voz del poemario de Vallejo han, en efecto, buscado y encontrado otra España, pero es una España muy distante a la que imagina o añora la voz que les habla.

\section{Referencias}

\section{Diario de Colón. http://www.traduccionliteraria.org/1611/esc/america/diario.htm}

El País. Entrevista con Fernando Iwasaki. Autor de 'España, aparta de mí estos premios. cultura.elpais.com/cultura/2009/10/07/actualidad/1254931200_1254936964.html 


\section{Carmen Tisnado}

Honores, E. Discurso inaugural, en simposio Construcciones de la otredad. La Casa de la Literatura Peruana; Lima, Perú. 17 y 18 de mayo del 2012.

Iwasaki, F. (2009). España, aparta de mí estos premios. Madrid: Páginas de espuma.

Ojo Seco. 30 de octubre de 2012. Entrevista a Fernando Iwasaki, disponible en http://paginasdeespuma.com/blog/fernando-iwasaki-en-ojoseco-cl/

Ortega, J. (1982). Vallejo: la poética de la subversión. Hispanic Review, 50 (3) 267-296.

Real Academia Española. Diccionario de la Lengua Española. Madrid, 1984, vigésima edición.

The Bible: https://www.biblegateway.com

Vallejo, C. España, aparta de mí este cáliz. www.literatura.us/vallejo/caliz.html

Vera, P. (2009). Fernando Iwasaki, escritor. Acercamiento práctico al mundo de los 'Premios Búfalo' y los cuentos clonados. Diario de Cádiz, 16/11/. http://www.diariodecadiz.es/ocio. 